\title{
Application of Velocity Variation with Angle (VVA) Method on an Anisotropic Model with Thomsen Delta Anisotropy Parameters
}

\author{
Pengujian Metode Velocity Variation with Angle(VVA) pada Model Anisotropi dengan Parameter
}

\section{Anisotropi Thomsen Delta}

\author{
Waskito Pranowo ${ }^{1 *}$, Sonny Winardhi ${ }^{2}$ \\ 1 Teknik Geofisika, Universitas Pertamina, Jakarta, Indonesia \\ ${ }^{2}$ Teknik Geofisika, Institut Teknologi Bandung,Bandung, Indonesia \\ *Email: wpranowo@universitaspertamina.ac.id
}

Submit: 4 Juli 2018; Revised: 4 September 2018; Accepted: 10 September 2018

\begin{abstract}
Anisotropic properties will influence seismic propagation, for example it will affect wave velocity. One of well-known anisotropi equation for Transversaly Isotropic media is weak anisotropy with Thomsen's notation. Thomsen's equation uses $V_{P 0}$, notation $\delta$ and $\epsilon$ in P-wave velocity equation. Supriyono [2011] tried to estimate all of these variables by using velocity variation with angle (VVA) attribute. This research uses synthetic data, which is CMP Gather to know limitations of VVA attribute, to identify the error values, and to determine the best indicator of anisotropic effect. This research also uses another analysis method, which is grid search inversion to estimate $V_{P 0}$ and $\delta$. From this research, Both VVA and grid search invesion still produce signficant error. The effects which will appear because of anisotropic property's presence are hockey-stick and over NMO-stretching.
\end{abstract}

Keywords: Anisotropy, VVA,grid search, hockey-stick, over NMO -stretching

\begin{abstract}
Abstrak: Sifat anisotropi suatu media mempengaruhi propagasi gelombang seismik, dalam hal ini adalah kecepatan gelombang. Salah satu jenis persamaan anisotropi yang dikenal untuk kasus Transversaly Isotropic adalah anisotropi lemah dengan parameter anisotropi Thomsen. Parsamaan Thomsen menggunakan $V_{P 0}$ dan notasi $\delta$ serta $\epsilon$ dalam persamaan kecepatan gelombang P. Supriyono [2011] berusaha mengestimasi variabel tersebut menggunakan atribut velocity variation with angle (VVA). Pada penelitian ini digunakan data sintetik berupa CMP Gather untuk melihat batasan-batasan apa dari atribut VVA dan sebesar apa kesalahan yang terjadi serta untuk melihat efek yang dapat dijadikan indikator adanya anisotropi. Selain itu digunakan analisis lain berupa inversi grid search untuk mengestimasi variabel tersebut. Dari hasil penelitian ini didapatkan bahwa kedua metode tersebut masih memberikan nilai kesalahan yang cukup signifikan.Efek-efek yang terjadi akibat adanya anisotropi adalah munculnya hockeystick dan over NMO-stretching.
\end{abstract}

Kata kunci: Anisotropi, VVA, grid search, hockey-stick, over NMO -stretching

\section{PENDAHULUAN}

Banyak reservoir hidrokarbon yang memiliki sifat anisotropis sebagai contoh, basement fracture, perselingan lapisan tipis, dan lain lain. Sifat anisotropis ini mempengaruhi propagasi gelombang seismik, dalam hal ini adalah kecepatan gelombang. Thomsen (1986)? melakukan penyerdahaan salah satu jenis anisotropi yaitu Transversaly Isotropic (TI). Thomsen mengajukan notasi-notasi yang digunakan dalam penyederhanaan kecepatan gelombang. Supriyono [2011] mengajukan suatu metode untuk mengestimasi parameter anisotropis Thomsen ini dari data seismik.Metode ini disebut atribut Velocity Variation with Angle (VVA). Dalam atribut VVA ini, Supriyono [2011] juga mengajukan persamaan root mean square velocity ( $V_{R M S}$ ) depend offset untuk mengestimasi parameter anisotropis pada kasus reservoir batuan klastik. Dalam penelitian ini, dilakukan pengaplikasian atribut $V V A$ tersebut untuk kasus anisotropi lainnya yaitu ketika, dan melihat sebesar apa kesalahan yang terjadi ketika menggunakan atribut $V V A$ ini dalam estimasi parameter anisotropis Thomsen.

\section{TEORI}

\subsection{Notasi Thomsen pada Weak Elastic Anisotropy}

Thomsen [2002] mengajukan notasi yang sesuai untuk medium Transversaly Isotropic yang hanya berlaku untuk kasus anisotropi lemah. Untuk gelombang P, kecepatan fasanya didekati oleh,

$$
V_{P}(\theta) \approx V_{P}\left(1+\delta \sin ^{2} \theta+(\epsilon-\delta) \sin ^{4} \theta\right.
$$

dengan $\theta$ adalah sudut antara ray dengan sumbu $x_{3}$ (sumbu z), $V_{P} 0$ adalah kecepatan vertikal, $\epsilon$ dan $\delta$ berturutturut adalah parameter anisotropis Thomsen,

$$
\delta=4\left(\frac{V_{P}\left(45^{\circ}\right)-V_{P 0}}{V_{P 0}}\right)-\epsilon, \epsilon=\frac{V_{P}\left(90^{\circ}\right)-V_{P 0}}{V_{P 0}},
$$


Supriyono (2011) menyederhanakan persamaan 1 untuk sudut kecil dengan asumsi $(\epsilon-\delta) \sin ^{4} \theta \ll \delta \sin ^{2} \theta$ sehingga,

$$
V_{P} \approx V_{P 0}\left(1+\delta \sin ^{2} \theta\right)
$$

\subsection{Huruf dan Spasi}

Transformasi dari offset menjadi sudut dihitung dengan persamaan Walden [1991],

$$
\sin \theta=\frac{(x)\left(V_{i n t}\right)}{(t w t)\left(V_{R M S}\right)^{2}}
$$

dengan $x$ adalah offset, twt adalah two-way travel time, $V_{\text {int }}$ dan $V_{R M S}$ adalah berturut-turut kecepatan interval dan kecepatan root-mean-square di setiap twt. Persamaan Walden berlaku untuk kasus isotropis. Sedangkan untuk kasus anisotropis, transformasi offset ke sudut dilakukan dengan menggunakan hubungan,

$$
x=\sin \theta_{N}\left(\sum_{i=1}^{N} \frac{V_{P 0 i} \cdot t_{i n t 0 i}}{\sqrt{V_{N}^{2}-V_{i}^{2} \sin ^{2} \theta_{N}}} \cdot V_{i}\right),
$$

dengan, $V_{N}$ kecepatan $\mathrm{P}$ interval ke- $N$ (daerah target), $V_{i}$ kecepatan $\mathrm{P}$ interval ke- $i$ (di setiap twt), $x$ offset, $t_{\text {int0i }}$ interval waktu (two way) lapisan ke- $i, \theta_{N}$ angle of incidence lapisan ke- $N$ (target). Penurunan hubungan offset dengan sudut diatas berasal dari raytracing (Hukum Snell). Serupa dengan hubungan offset dengan sudut, twoway travel time daerah target $\left(T W T_{N}\right)$ pada kasus isotropis maupun anisotropis dapat dihitung melalui persamaan,

$$
T W T_{N}=V_{N}\left(\sum_{i=1}^{N} \frac{V_{P 0 i} \cdot t_{i n t 0 i}}{V_{i} \sqrt{V_{N}^{2}-V_{i}^{2} \sin ^{2} \theta_{N}}}\right)
$$

\section{$2.3 \quad V_{R M S}$ Variation with Offset}

Supriyono (2011), memformulasikan $V_{R M S}$ variation with offset (VVO) dengan menggunakan persamaan,

$$
\frac{1}{V_{R M S}-j}=\frac{\left(\Delta t_{j}+T_{j}^{2}\right)-T_{0}^{2}}{X_{0}^{2}}, T_{j}=\sqrt{T_{0}^{2}+\frac{X_{j}^{2}}{V_{s t k}^{2}}}
$$

dengan $T_{j}$ adalah waktu tempuh pada offset $X_{j}, V_{\text {stk }}$ adalah untuk kecepatan untuk koreksi NMO, $\Delta t_{j}$ adalah time residual moveout yang merupakan pergeseran waktu yang dihitung dengan menggunakan Local Event Correlation. Dari persamaan di atas dapat dilihat bahwa $V_{R M S}$ dihitung secara bebas setiap offset. Setelah perhitungan VVO, dilakukan analisis Velocity Variation with Angle dengan menggunakan alur kerja sebagai berikut

\subsection{Grid Search}

Grid search adalah salah satu metode inversi global. Pada grid search ruang model didefinsikan terlebih dahulu dengan menentukan interval harga setiap parameter model yang mungkin yang didiskretisasi [Grandis, 2009]. Setiap grid merepresentasikan satu sampel parameter yang harus dimodelkan ke depan. Parameter yang sesuai adalah yang

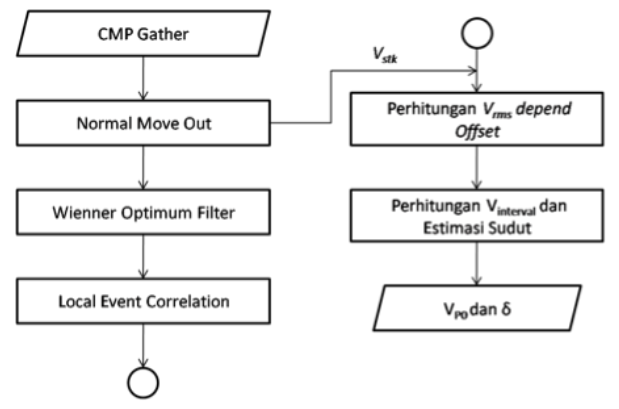

Gambar 1. Alur kerja metode Velocity Variation with Angle

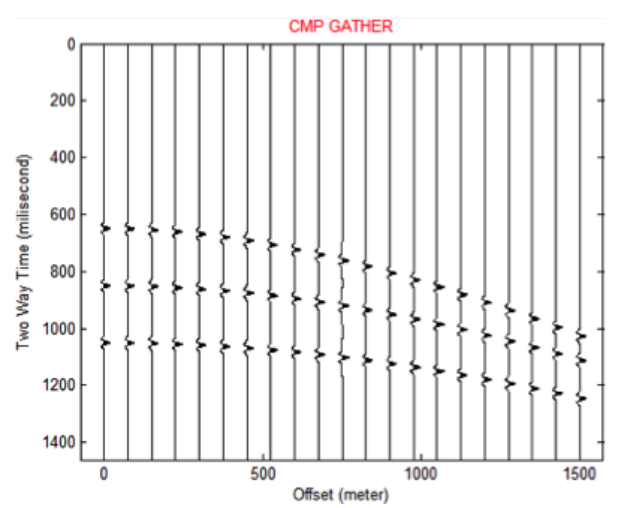

Gambar 2. CMP Gather. Lapisan antara reflektor-1 dan reflektor-2 merupakan lapisan anisotropi

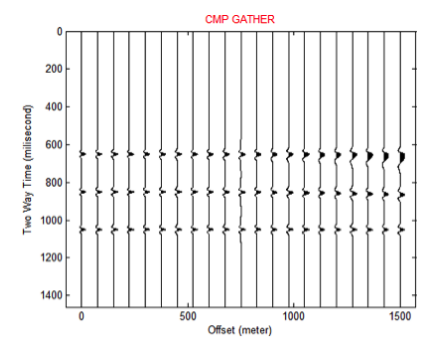

Gambar 3. Hasil Koreksi NMO pada CMP Gather

memiliki perbedaan terkecil antara pemodelan ke depan dengan data.

\section{PEMODELAN DAN HASIL}

\section{1 pemodelan data sintetis}

Model lapisan yang dibentuk pada penelitian ini adalah sebagai berikut,

1. Lapisan- 1 , twt $=0 \mathrm{~ms}-650 \mathrm{~ms}, \delta=0, \epsilon=0$

2. Lapisan-2, twt $=650 \mathrm{~ms}-850 \mathrm{~ms}, \delta=0.1329, \epsilon=0$

3. Lapisan-3, twt $=850 \mathrm{~ms}-1050 \mathrm{~ms}, \delta=0, \epsilon=0$

4. Lapisan-4, twt $=1050 \mathrm{~ms}, \delta=0, \epsilon=0$

Dari data diatas dengan offset $0-1500 \mathrm{~m}$ didapatkan model CMP Gather sebagai berikut,

Dari data CMP Gather dilakukan koreksi NMO untuk melihat adanya efek anisotropi seperti yang terlihat di gambar 3 . 


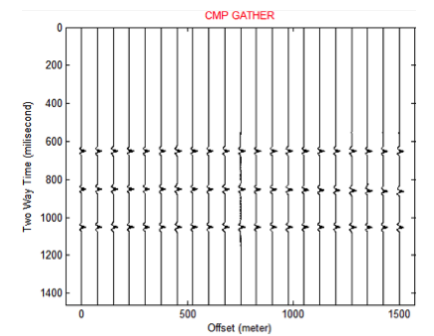

Gambar 4. Hasil Wiener Deconvolution pada CMP Gather

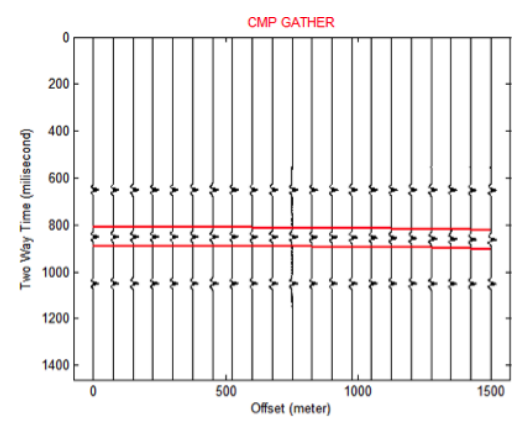

Gambar 5. Local Event Correlation pada CMP Gather

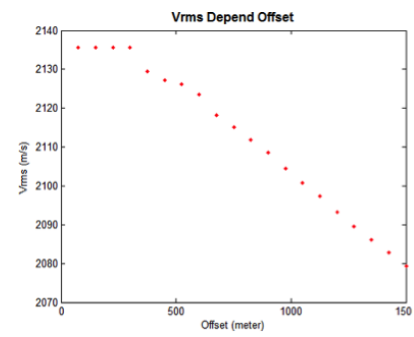

Gambar 6. $V_{R M S}$ variation with offset

Dari gambar 3 terlihat terjadi efek NMO-stretching. Fenomena ini dapat menyebabkan kesalahan pada saat dilakukan Local Event Correlation (LEC). Untuk menghilangkan efek stretch ini dilakukan Wienner Filter.

Kemudian dilakukan LEC untuk mendapatkan time residual. Lebar window yang digunakan dalam LEC adalah sebesar $80 \mathrm{~ms}$, dengan target reflector kedua pada kedalaman $850 \mathrm{~ms}$.

Setelah mendapatkan time residual, maka dilakukan perhitungan VVO menggunakan persamaan 7. Hasil dari perhitungan VVO dapat dilihat pada Gambar 6.

Dari hasil VVO, dilakukan transformasi $V_{R M S}$ menjadi $V_{\text {int }}$ dengan menggunakan formula Dix dan transformasi offset menjadi sudut dengan menggunakan formula Walden. Lalu, untuk melakukan estimasi $V_{P 0}$ dilakukan plot antara $V_{\text {int }}$ dan $\sin ^{2} \theta$ sebagai berikut,

Dari plotting didapatkan persamaan garis $V_{\text {int }} \theta$ $=2.804-0.333 \sin ^{2} \theta$ dengan menggunakan regresi linear. Dari persamaan tersebut dapat dilakukan estimasi $\delta$ dan $V_{P 0}$

$$
V_{P 0}=V_{\text {int }}(0)=2.804 m / m s \delta=-\frac{0.333}{V_{P 0}}=-0.119 .
$$

Sehingga, didapatkan nilai sebesar $V_{P 0} 2804.2 \mathrm{~m} / \mathrm{s}$ dan

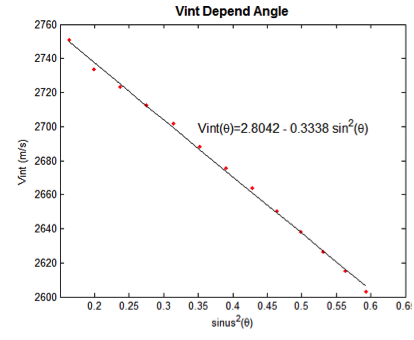

Gambar 7. Vint variation with angle

Tabel 1. Perbandingan model input dan estimasi, serta hasil error dengan menggunakan metode VVO

\begin{tabular}{|c|c|c|c|}
\hline & Model Input & Estimasi & Eror \\
\hline$V_{P 0}$ & $2456.4 \mathrm{~m} / \mathrm{s}$ & $2804.2 \mathrm{~m} / \mathrm{s}$ & $14.16 \%$ \\
\hline$\delta$ & 0.1329 & -0.119 & $189.5 \%$ \\
\hline
\end{tabular}

Tabel 2. Perbandingan model input dan estimasi, serta hasil error dengan menggunakan metode VVO

\begin{tabular}{|c|c|c|c|}
\hline & Model Input & Estimasi & Eror \\
\hline$V_{P 0}$ & $2456.4 \mathrm{~m} / \mathrm{s}$ & $2804.2 \mathrm{~m} / \mathrm{s}$ & $14.16 \%$ \\
\hline$\delta$ & 0.1329 & -0.119 & $189.5 \%$ \\
\hline
\end{tabular}

$\delta$ sebesar -0.119. Dari hasil tersebut didapatkan error sebagai berikut,

Ketidaktepatanestimasi pada metode VVO disebabkan metode ini sangat bergantung pada stacking velocity $\left(V_{\text {stk }}\right)$ yang digunakan pada koreksi NMO. Ketidaktepatan $V_{s t k}$ dapat menyebabkan ketidaktepatan estimasi $V_{P 0}$ sehingga menyebabkan pula kesalahan estimasi $\delta$, karena pada dasarnya $V_{P 0}$ dan $\delta$ merupakan pasangan yang tidak terpisahkan (Thomsen, 2002).

\subsection{VVA dengan grid search}

Untuk melakukan estimasi $V_{P 0}$ dan $\delta$ dengan metode grid search, data yang digunakan adalah dari CMP gather yang belum terkoreksi NMO. Reflektor yang diduga anisotropi, dilakukan picking pada two-way travel time (TWT). Data offset dan TWT reflektor menjadi input pada perhitungan. Domain parameter model yang akan dihitung adalah $V_{P 0}$ dengan grid sebesar 0.001 dan $\delta$ sebesar 0.01. Sebelum menghitung respon model, dilakukan estimasi sudut menggunakan persamaan 3. Kemudian nilai semua offset, $V_{P 0}$, dan $\delta$ dimasukan ke dalam persamaan waktu tempuh (pers. 6) untuk mendapatkan setiap respon model. Kemudian dihitung nilai $E_{R M S}$ antara respon model dengan data TWT. Kombinasi $V_{P 0}$ dan $\delta$ yang menghasilkan $E_{R M S}$ terkecil merupakan parameter terbaik. Dari inversi grid search didapatkan nilai parameter terbaik yaitu $V_{P 0}=2.515 \mathrm{~m} / \mathrm{ms}$ dan $\delta=0.13$.

Kesalahan yang terjadi pada metode inversi grid search ini berasal dari kesalahan estimasi sudut. Estimasi sudut yang digunakan menggunakan persamaan Walden (pers. 3) yang hanya baik untuk media isotropi.

Jika dilakukan inverse grid search dengan sudut yang benar didapatkan error yang sangat kecil yaitu $0.1 \%$ untuk $V_{P 0}$ dan $2 \%$ untuk $\delta$. Namun, estimasi sudut di media anisotropi sulit dilakukan. Estimasi sudut dengan menggu- 


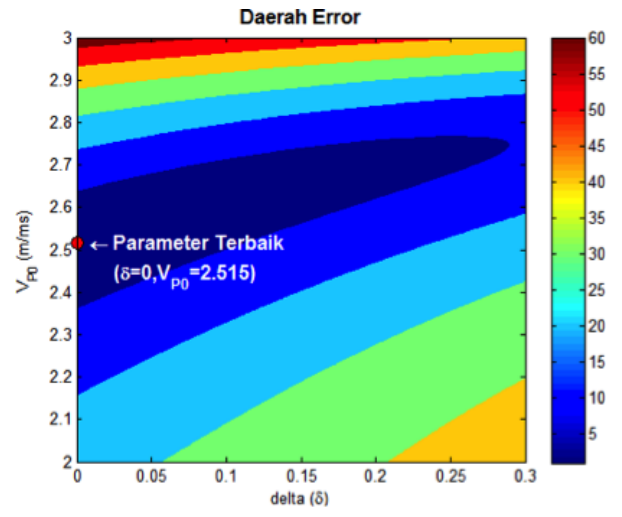

Gambar 8. Daerah $E_{R M S}$ parameter $V_{P 0}$ dan $\delta$ menggunakan variasi yang tepat

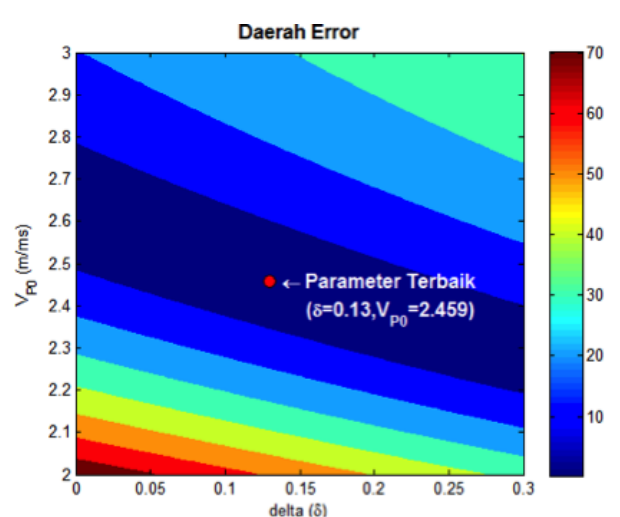

Gambar 9. Daerah $E_{R M S}$ parameter $V_{P 0}$ dan $\delta$ menggunakan sudut yang tepat

nakan persamaan 4 sulit dilakukan karena membutuhkan data yang lengkap untuk estimasinya yaitu data $V_{P 0}$ beserta parameter anisotropinya.

\subsection{Estimasi vertical velocity dari kurva $X^{2}-T^{2}$}

Karena merupakan faktor yang penting untuk melakukan estimasi $\delta$, maka dilakukan estimasi $V_{P 0}$ dari offset data CMP Gather. Data offset dan TWT reflektor yang lapisan tepat di atasnya merupakan lapisan anisotropi di-plot pada kurva $X^{2}-T^{2}$. Dengan mengasumsikan bahwa pada offset terdekat efek anisotropi belum terlalu berpengaruh, maka dilakukan pengestimasian nilai $V_{P 0}$ dari 2 data atau 3 data trace terdepan. Dari gradien masing-masing kurva didapatkanlah nilai kecepatan dan eror dengan sebenarnya sebagai berikut,

Dari hasil percobaan diatas dapat dilihat bahwa masih dihasilkan error. Walaupun untuk $\delta$ sebesar 0.1329 dan 0.1329 eror yang dihasilkan hanya berkisar 4-5\%, tetapi semakin besar nilai mutlak $\delta$ maka semakin besar eror yang dihasilkan.

\subsection{Indikator Anisotropi}

Adanya anisotropi menimbulkan efek pada data CMP Gather (data prestack). Efek-efek ini dapat digunakan sebagai indikator bahwa adanya lapisan anisotropi diatas reflektor tersebut yaitu hockey stick dan over NMO-stretching.

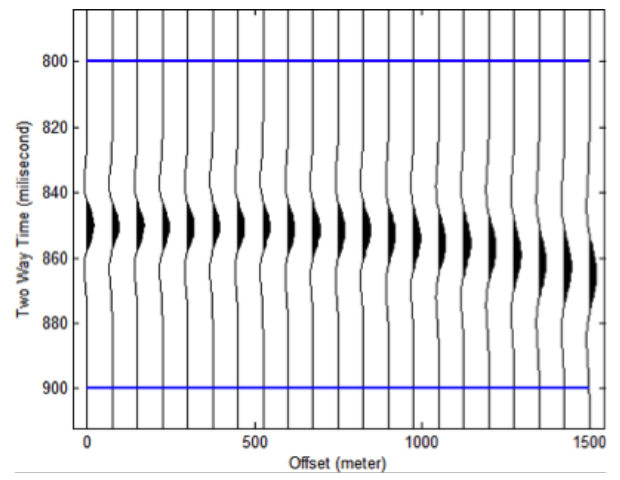

Gambar 10. Efek hockey-stick

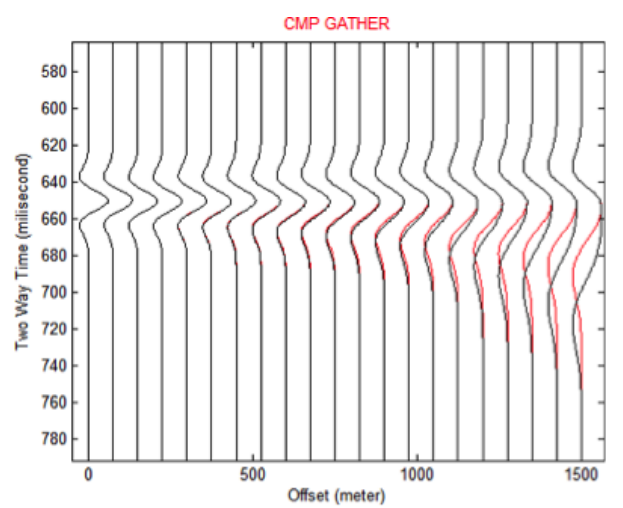

Gambar 11. OverNMO-stretchingpada media anisotropi (hitam) dan anisotropi( merah).

Efek hockey stick tidak terlalu terlihat ketika model anisotropi hanya menggunakan parameter anisotropis. Hal ini disebabkan karena pada far-angle, parameter anisotropis $\epsilon$ lebih berpengaruh daripada $\delta$.

Untuk indikator lainnya, yaitu efek over NMOstretching dapat terlihat ketika memiliki nilai $\delta$ positif atau $\delta$ $>\epsilon$. Jika dibandingkan antara media anisotropi dan isotropi, stretching yang terjadi setelah koreksi NMO pada kasus anisotropi lebih besar daripada kasus isotropi.

Jika kecepatan yang digunakan dalam koreksi NMO $\left(V_{N M O}\right)$ mendekati nilai $V_{P 0}$, maka efek stretching ini akan berkurang. Hal ini dapat dijadikan indikator yang baik dalam estimasi $V_{P 0}$.

\section{KESIMPULAN}

Baik metode VVO dan grid search masih menghasilkan error yang cukup signifikan dalam pemisahan $V_{P 0}$ dengan $\delta$ pada kasus $\epsilon=0$. Eror yang dihasilkan pada metode VVO disebabkan kebergantungan metode ini pada estimasi $V_{P 0}$. Sedangkan eror yang dihasilkan pada metode inversi grid search disebabkan karena kesalahan estimasi sudut. Percobaan estimasi $V_{P 0}$ dengan kurva $X^{2}-T^{2}$ juga masih menghasilkan eror yang cukup signifikan. Pada kasus anisotropi $\epsilon=0$ muncul efek-efek yang dapat menjadi indikator adanya lapisan anisotropi yaitu hockey-stick dan over NMO-stretching. Efek over NMO-stretching ini dapat dijadikan indikator yang cukup baik dalam estimasi $V_{P 0}$ 
Tabel 3. Perbandingan Nilai Asli, estimasi, dan error dari CMP Gather

\begin{tabular}{|c|c|c|c|c|c|c|}
\hline & \multicolumn{3}{|c|}{ Parameter anisotropis $(\delta)$} & & & \\
\hline & \multicolumn{2}{|c|}{$\delta=0.1329$} & \multicolumn{2}{|c|}{$\delta=0.2658$} & \multicolumn{2}{|c|}{$\delta-0.119$} \\
\hline & 2 trace & 3 trace & 2 trace & 3 trace & 2 trace & 3 trace \\
\hline Asli $(\mathrm{m} / \mathrm{s})$ & 2036 & 2036 & 2036 & 2036 & 2036 & 2036 \\
\hline Estimasi $(\mathrm{m} / \mathrm{s})$ & 2137 & 2137 & 2253 & 2253 & 1950 & 1954 \\
\hline Error(\%) & 4.95 & 4.95 & 10.66 & 10.66 & 4.23 & 4.04 \\
\hline
\end{tabular}
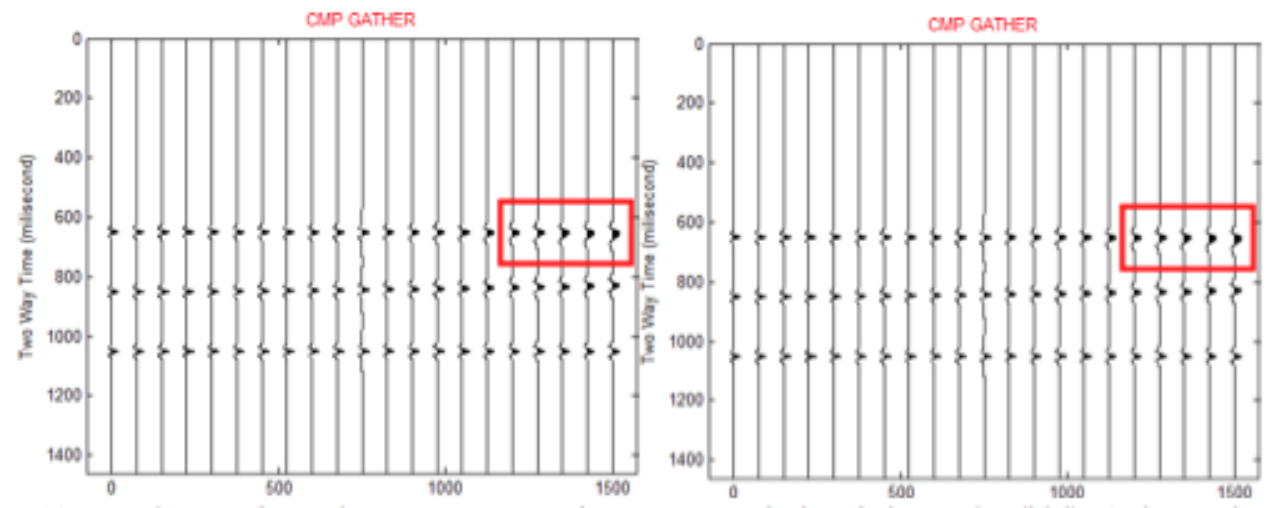

Gambar 12. NMO-stretching dengan menggunakan $V_{P 0}$ untuk koreksi NMO. (kiri) Anisotropis, (kanan) Isotropis.

karena efek ini semakin berkurang dengan semakin tepatnya estimasi $V_{P 0}$.

\section{DAFTAR PUSTAKA}

Grandis, H. 2009. Pengantar Pemodelan Inversi Geofisika. Penerbit Himpunan Ahli Geofisika Indonesia, Jakarta

Supriyono. 2011. Velocity Variation with Angle or Offset (VVO), A New Tool for Direct Hydrocarbon Indicator: Case Studies in Low and High Impedance Clastic Reservoir . Disertasi Doktoral ITB.

Thomsen, L. 2002. Understanding Seismic Anisotropy in Exploration and Exploitation. Society of Exploration Geophysicists: Tulsa.

Walden, A.T. Making AVO sections more robust. Geophysical Prospecting, Vol. 39, p. 915-942. (1991) 